\title{
LA TEORÍA DE LA LITERATURA COMO METODOLOGÍA DE ESTUDIO DEL PAISAJE CULTURAL
}

\author{
THE THEORY OF LITERATURE AS A METHODOLOGY \\ FOR STUDYING THE CULTURAL LANDSCAPE
}

María Isabel MORALES SÁNCHEZ

Universidad de Cádiz isabel.msanchez@uca.es

\begin{abstract}
Resumen: Este trabajo tiene como objeto evidenciar el valor de la teoría de la literatura como metodología transversal y plural, que, en estrecho contacto con otras disciplinas y metodologías convergentes, como la Retórica cultural, la Literatura Comparada o los Estudios culturales, permite profundizar en el estudio de la literatura como discurso de construcción e interpretación del paisaje cultural. Para ello nos situamos desde una perspectiva que aúna, desde el punto de vista teórico, los elementos que configuran el discurso artístico - en este caso concreto, el literario- con la explicación y especificación de su componente cultural. La estrecha conexión establecida por la tradición entre los estudios poético-retóricos, establece un marco excepcional para abordar líneas de investigación sobre el paisaje poco atendidas hasta el momento, más allá del ámbito de los estudios específicamente literarios.
\end{abstract}

Palabras clave: paisaje, literatura, teoría de la literatura, discurso cultural, retórica.

Abstract: The aim of this work is to highlight the value of literary theory as a transversal and plural methodology, which, in close contact with other converging disciplines, allows us to study literature in greater depth as a discourse in which cultural landscapes are constructed and interpreted. In order to do so it is necessary to consider a perspective that combines, from a theoretical point of view, the elements that make up artistic discourse -in this specific case, the literary discourse- ${ }^{-}$with the explanation and specification of its cultural components. The close connection traditionally established between rhetorical and poetic studies creates an exceptional framework for tackling lines of research on cultural landscapes that have so far been neglected since they go beyond the scope of literary studies.

Keywords: Landscape, Literature, Theory of literatura, Cultural Discourse, Rhetoric 


\title{
$1^{\text {Irmanaction }}$
}

\begin{abstract}
A la luz del día, también las bodegas eran otras. Recién dejado su vivir nocturno, sólo quedaban ya restos de él en las sombras altas de las columnas, en las bóvedas casi indistinguibles y acribilladas de diminutos trazos negros: las deyecciones de los murciélagos que, a la noche, convertían la clara catedral del vino en un tibio pandemónium de alas tenues y roces furtivos, de monstruosos hociquillos, vagos chillidos espaciados, leves choques aéreos. Pero la claridad lo cambiaba y serenaba todo. Entre la filtrada luz mañanera, entraban los hombres al trabajo; los ratones aparecían más tarde.

Fernando Quiñones, "Muerte de un Semidiós" Cinco historias del vino
\end{abstract}

Las líneas que siguen a continuación pretenden potenciar estrategias transversales de trabajo, en el marco de los estudios universitarios, que pongan de relieve la importancia de la literatura como una fuente imprescindible para el análisis e interpretación del paisaje. Estrechamente ligado a esta idea, creemos que es difícil promover estudios rigurosos multidisciplinares sin que el acercamiento a la literatura se produzca desde el conocimiento de sus resortes esenciales, sin la consciencia de sentirla como un modo de construcción de la realidad que hace de ella un poderoso recurso de conversión, transgresión y trasposición semántico, simbólico y conceptual. En este sentido, disciplinas como la Teoría de la literatura vienen proporcionando, en el ámbito de la investigación, metodologías eficaces para el análisis de los resortes que articulan la dinámica literaria, así como conceptos que permiten describir y valorar la confluencia de otros discursos culturales en ella. Entendidas en su sentido más amplio y aglutinador, tanto la Teoría de la literatura como la Literatura comparada son reveladoras en el estudio del paisaje, pues hacen evidentes muchos de los esquemas que, fijados por el imaginario colectivo, proceden de la tradición literaria, pero no son siempre identificados como tales. A veces, el lector (incluso especializado) desconoce que esa imagen, idea o valor preservado en su cultura tiene como origen un texto literario o, incluso, que dicho texto haya surgido por influencia de otros discursos no artísticos. De manera paralela, el importante desarrollo que los estudios sobre el paisaje -tanto desde el punto de vista teórico como práctico- ha tenido en los ámbitos de la geografía, y de las artes plásticas, no ha suscitado un desarrollo similar en otras disciplinas -sin obviar las importantes aportaciones, por supuesto, realizadas por la tematología- con la consiguiente reducción de temas y enfoques. Sin embargo, parece que esta permeabilidad hacia distintos espacios del conocimiento, viene de la mano, en los últimos años, del repunte y vuelta de interés provocado por las corrientes ecológicas de pensamiento, cuyo punto de mira se ha centrado en la relación del hombre con la naturaleza, desde una perspectiva que "implica a la vez que un enfoque científico, también una actitud y un estado mental holístico hacia el conocimiento del paisaje y los fenómenos ecosistémicos" (Etter, 1991: 3). La complejidad en el estudio de este concepto y de sus diversas manifestaciones verbales y no verbales hace necesaria la existencia de estudios transversales en los que se aúnen las perspectivas literaria, histórica, científica, antropológica, social o económica, no como una suma o sucesión, sino como un conjunto integrado y conectado que permita conectar todos los discursos implícitos alrededor de un 
movimiento cultural o de un ideario específico. Ver un artículo sobre literatura en un volumen de estudios histórico-económicos, o viceversa, constituye todavía una rara avis que difícilmente no sorprende a quien lo hojea. Por otra parte, en muchas ocasiones, el acercamiento a lo literario desde otros ámbitos se concentra en la anécdota, dando como resultado una serie de citas que aluden a referencias esencialmente vinculadas con el espacio (una categoría literaria esencial para abordar el paisaje en la literatura, pero no la única) haciendo referencia a lugares que corroboran la recreación de un territorio, pero pocas veces que se extiendan a una profundización en las razones por las que la recreación literaria genera dichos símbolos o valores. De hecho, no es casual la tendencia que reivindica la necesidad -en el ámbito de la formación y de la investigación- de una formación integral que facilite la creación de equipos y redes interdisciplinares capaces de abordar distintas vertientes de un mismo tema o problema. Desde el punto de vista de la lectura y de la formación de lectores en la universidad, un aspecto sobre el que venimos trabajando reiteradamente, la inclusión de los textos literarios para la enseñanza de otras disciplinas resulta, de la misma manera, una estrategia tremendamente fructífera, aunque, de nuevo, debemos prestar mucha atención a las formas de lo que podríamos denominar el adiestramiento literario (decía Wilde que la literatura no es objeto de enseñanza sino de temperamento) de manera que la literatura acabe siendo considerada un recurso imprescindible y no una imposición caprichosa. En este sentido, este breve acercamiento también pretende alcanzar un segundo objetivo: subrayar la relevancia que, para la comprensión de un hecho histórico, un hábito cultural o un uso social específico, posee la lectura literaria. El estudio del paisaje y de su concepto, tan usual en las enseñanzas vinculadas a lo geográfico y a lo económico, a lo patrimonial -artístico o industrial, material o inmaterial - o a la gestión cultural, por poner algunos ejemplos, obvian, en la mayoría de las ocasiones, incluso sin prejuicio reconocido, el discurso literario, porque se considera "natural" que la literatura sea materia específica de otros espacios del conocimiento, aun cuando resultaría más que obvio, que un texto como el que abre esta introducción, ayudaría a explicar, no sólo una rica tradición literaria, cuyos textos testimonian, desde la literatura latina hasta la contemporánea, pasando por Tirso, Lope, Quevedo o el mismo Shakespeare, la presencia ineludible del mundo vitivinícola en nuestra cultura y sus representaciones artísticas, sino también las razones de nuestra posición privilegiada en el comercio Europeo e Hispanoamericano, con el Puerto de Cádiz como referencia durante los siglos XVIII y XIX, el pensamiento económico que lo sustenta o su conexión con el desarrollo científico de la navegación. De la misma manera, textos como la Dorotea de Lope, El hereje de Delibes, El hijo de la filoxera de Gonzálo Gómez, La bodega de Blasco Ibáñez o La Templanza de María Dueñas, nos introducen en el conocimiento de un universo que gira en torno a la vitivinicultura y también al urbanismo derivado de esta actividad. Baste recordar cómo la arquitectura de la bodega, y su situación privilegiada en algunas ciudades del sur, responde, entre otras razones, a un tipo de arquitectura (vinculada a la burguesía comerciante) en la que la tipología básica de las casas-palacio barrocas se transforman para adecuarse a la actividad comercial, incluso, en pleno centro de la ciudad (Barros Caneda, 1996: 350). La construcción del imaginario colectivo alrededor de la bodega está construida a partir de una amalgama de discursos sociales, económicos, 
ideológicos y culturales que no deberían ser analizados por separado, pues son los que conforman parte de nuestra identidad. La propia funcionalidad de lo urbano y la concepción de la ciudad - usadas como arsenales, enclaves defensivos, centros económicos- en cada momento histórico es absorbida por la literatura y el arte y, por lo tanto, leída e interpretada desde un punto de vista estético que resulta indisoluble de un modo de pensamiento y de concepción de la realidad. No sé si es oportuno afirmar que, en los últimos años, cada vez me asalta más la duda de que este desinterés por abordar de modo integral la formación no esté arraigado sólo en el desconocimiento de su rentabilidad, sino en las deficiencias lectoras que han originado la paulatina exclusión de la literatura de nuestros hábitos y necesidades cotidianos. De ahí que algunas voces lleven años insistiendo en la necesidad de sustituir la idea de enseñar por la de "enseñar a apreciar la literatura" (Mendoza Fillola, 2001), de tal forma que el trabajo se centre en revelar la capacidad del discurso literario para ayudar a comprendernos y reconocernos. Supongo que, al mismo tiempo, nosotros mismos nos hemos "limitado" por creer que incurríamos en injerencias impropias y nocivas para la propia enseñanza de la literatura o que traicionábamos la rigurosidad de su enseñanza. Ahora, cuando el mundo digital ha hibridado aún más lo que ya de por sí era híbrido, cuando ha planteado nuevas formas de expresar/ocultar/simular la identidad, cuando ha irrumpido alterando los hábitos de lectura y escritura y ha extralimitado las fronteras textuales de lo literario, resulta una gran oportunidad para restablecer el interés por potenciar el estudio de la literatura de manera transversal y convergente, amplificando su proyección en diferentes ámbitos artísticos y científicos.

\section{El concepto de paisaje y su aplicación a la literatura}

Nosotros somos un montaje artístico y nos quedaríamos estupefactos si se nos revelara todo lo que en nosotros procede del arte. Lo mismo ocurre con el paisaje, uno de los lugares privilegiados donde se puede verificar y medir este poder estético

Alain Roger, Breve tratado del paisaje

Tal y como comentábamos con anterioridad, son los ámbitos de la Geografía y de la Historia del Arte los que han concitado un mayor número de estudios alrededor del Paisaje, si bien es verdad que no siempre con el mismo grado de aceptación. En 1992, dicho concepto se traslada al ámbito del patrimonio, tras el reconocimiento en la Guía para la implantación del Comité de Patrimonio Mundial, siendo definido en el año 2000 como "cualquier parte del territorio tal como la percibe la población, cuyo carácter sea el resultado de la acción y la interacción de factores naturales y/o humanos" (2000: 107) en el marco del convenio europeo firmado en Florencia en el año 2000. La revisión de la abundante documentación existente, desvela una fundamentada preocupación por potenciar políticas que desarrollen y asienten el valor del paisaje como parte de la memoria y de la herencia patrimonial, ligada a los procesos culturales que han hecho que un territorio concreto sea entendido por la población a partir de los valores conservados, vinculados no sólo al uso sino también a las representaciones realizadas del mismo. Pero si hay algo que los diferentes estudios teóricos sobre el concepto de paisaje 
han puesto de relieve -sobre todo desde la prevalencia de la escuela francesa en un importante período del siglo XX- es el componente emocional del mismo. Para Alain Roger, cuya teoría de perspectiva culturalista constituye un referente,

[...] la percepción de un paisaje, esa invención de los habitantes de las ciudades, supone a la vez, distanciamiento y cultura, una especie de recultura. Desde este presupuesto, los habitantes del mundo rural, por su simbiosis con el territorio y su íntima conexión con él, tendrían más lejano ese distanciamiento, esencial para construir el paisaje (2007: 32)

A este modo de percibir el paisaje como representación cultural o proyección mental en el territorio le sucederían otras tantas - sintetizadas por Besse en su ensayo "Las cinco puertas del paisaje" (2006: 145-171) - que entienden el paisaje, con relación a o como consecuencia del uso que se hace de él; bien como entorno material (en el sentido de Descola); bien como modo de actuar sobre la naturaleza con una intención de adecuarla a las necesidades (en la línea de la fenomenología) -territorio fabricado- y por último, como "proyecto" en consonancia con las tendencias ecológicas que pretenden ver el territorio de manera integral. De todas ellas resulta sugerente explorar, cómo están derivadas de una pregunta esencial: cuál es la relación del hombre con el territorio. De ahí que, en conexión con lo artístico, resulta interesante explorar cómo entiende la literatura esta relación, por cuanto puede expresar situaciones jerárquicas (dominio, sumisión) o simbióticas (integración fusión) y este aspecto tiene mucho que ver con el modo en el que las distintas corrientes literarias entienden, incluso, el objeto poético. Asimismo, y de forma paralela, tendríamos la idea del "distanciamiento" - ¿objetivo/subjetivo?, ¿interesado/desinteresado?- que nos llevaría, por ejemplo a pensar en que la configuración del viaje como motivo literario esencial respondería, entre otras razones a su consideración como elemento catalizador y generativo de la construcción del paisaje, siendo el elemento estructurador que permite experiencia y observación, por lo tanto, el que permite explorar ese reconocimiento de nuestra identidad a través de la aceptación de la existencia del otro. Toda observación produce distanciamiento, proporcionando un marco donde el sujeto se sitúa fuera de la escena, produciendo lo observado una impresión. La mirada del otro, de quien no habita allí, de quien no está en estrecha comunión con la tierra, del extraño, es la que configura una reinterpretación de la misma, una lectura distinta a la cotidiana. En el mismo sentido, la rememoración de los paisajes que han influido en nosotros, o que los habitantes de un lugar recuerdan, a través de la memoria, es otra forma de distanciamiento que permite la relectura y la reconstrucción de los paisajes. El carácter dinámico, por lo tanto, inherente al paisaje, incluye una variación no sólo física sino también cultural, en función de cada interpretación dada, por lo tanto, puede ser entendido como una convención que, como tal, "varía de una cultura a otra y, también, de una época a otra" (Maderuelo, 2010: 575). Sea cual fuere el ámbito tomado como referencia: científico (observación), apropiación social (utilidad) o estético (artístico), lo que sí parece evidente es que en la noción de paisaje hay un elemento esencial, esto es, la reflexión del individuo sobre su relación con la naturaleza. Para Zimmer (2008: 29) esta relación está estrechamente ligada a un modelo de mundo, siendo, además, consecuencia del mismo. De ahí que los lugares son objetos culturales y naturales al mismo tiempo. Pero, de forma paralela, 
advertimos que la naturaleza no es gótica, ni misteriosa, ni onírica, siendo la lectura que hacemos de ella las que acaban otorgando un sentido específico o a los lugares en una determinada tradición cultural.

Es, entendemos, a partir de este planteamiento donde la emoción estética desarrolla un papel esencial y donde la literatura -que es un producto cultural- no sólo asume prácticas culturales generadas desde otros ámbitos, sino que produce contextos específicos nuevos que se unen a ellos.

En este sentido, al paisaje le ocurre como a la mariposa: para llegar a existir debe sufrir una doble mutación. En primer lugar, debe nacer como oruga o fenómeno concreto - cierta vista, cierta panorámica, cierto país- y, en segundo lugar, debe transformarse en mariposa o idea estética. Esa mariposa puede ser diurna, bellísima y rica en colores -Bellavista, Vistalegre- o nocturna, fea, apolillada y hasta terrorífica -Malpaso, Tierramala-. En todo caso, siempre se caracterizará por su aura estética, esto es, por ser sentida o juzgada estéticamente. Sólo aquella investigación que tenga en cuenta que el paisaje es como la mariposa y que para entender su génesis debe contemplarse esa doble mutación nos dará la medida exacta de su naturaleza. (López Silvestre, 2009: 98)

Así podríamos afirmar que la literatura es, de una parte, un medio para “experimentar", leer e interpretar el paisaje de forma transversal, pues en ella se entrecruzan desde el pensamiento y la historiografía hasta la tecnología o la ciencia; es un arte especialmente permeable y sensible a los cambios experimentados por las comunidades en un territorio determinado y, por último, un soporte excepcional de sus diversas formas de manifestación histórica, estética o filosófica. Pero al tiempo que lee, la literatura crea, modifica y genera paisajes nuevos que se unen al imaginario colectivo de modo esencialmente verbal. Su propia esencia ficcional conlleva esta condición. De esta manera escribe, reescribe, interpreta, sobreinterpreta, inventa o reinventa la realidad, construyendo discursos que son asimilados en el acervo cultural. ${ }^{1}$ En su vinculación con el propio concepto de país, el paisaje literario sería, en palabras de Claudio Guillén, el "país verbal" en tanto paisaje transmitido esencialmente por el texto (Vilariño, 2004-2006:104), cuyo desarrollo se evidencia, sobre todo, en la novela y la poesía (Guillén, 1992: 95-98).

De forma concreta, estamos con Claudon cuando afirma cómo estudiar el paisaje en literatura remite a toda una serie de textos teóricos y producciones estéticas que se encuadran en un marco interdiscursivo (Claudon, 1996: 202), siendo estos los que proporcionan el espacio idóneo para analizar los motivos por lo que el individuo acaba interpretando o apreciando de una manera particular un territorio determinado. Esos discursos, integrados en el lingüístico, catalizan la construcción de una realidad distinta, de aquélla que define lo observado emocionalmente, la realidad de lo sensible y pensado. Desde un punto de vista antropológico-lingüístico, toda lengua imprime matices diferentes que marcan el modo en el que modelan la realidad, convirtiéndose en un sedimento histórico sobre el que planea la cosmovisión de distintas generaciones y grupos sociales (Diaz Rojo, 2004). Por extensión, la literatura ha contribuido culturalmente a crear un espacio transversal de confluencia de

\footnotetext{
${ }^{1}$ Bajo el nombre de Retórica Cultural y a partir de los presupuestos planteados por la semiótica de la cultura articulada desde Lotman en los años 60 del pasado siglo, esta perspectiva de análisis incide en la consideración de cualquier discurso como práctica cultural. Dicha perspectiva ha sido desarrollada en los últimos años desde el proyecto Retcult FFI201015160, dirigido por Tomás Albaladejo Mayordomo.
} 
realidades que configuran la expresión artística de dicha cosmovisión. En este sentido, el paisaje literario es una construcción de la imaginación "que va conformando paulatinamente una memoria, y que constituye una biografía de cada espacio, en continua mutación” (Hernández Guerrero, 2002: 75). Esta es una de las razones por las que el paisaje también forma parte de nuestra experiencia íntima, en la medida en que todos los lectores tenemos un paisaje que nos transformó nuestra manera de ver el mundo, en un momento determinado, y otros mediante los que lo interpretamos habitualmente.

Desde el punto de vista de la creación, es decir, de la construcción de valores, sentidos y significados, la dinámica literaria ofrece distintos enclaves desde los que abordar la relación del texto con el paisaje, entendiendo que la literatura no sólo interpreta o relee los ya construidos, sino que es capaz de generar otros nuevos que posteriormente serán asimilados por el imaginario. Tal y como afirmábamos al principio de nuestro breve acercamiento, la literatura y su estudio desde los conceptos propios articulados por la Teoría de la literatura ofrece no sólo la oportunidad de estudiar una historia de los paisajes, sino también las claves de su construcción discursiva, desde una perspectiva crítica y transversal. En primer lugar, los conceptos de ficción y verosimilitud nos sitúan en el centro mismo de la creación literaria, enfrentándonos a la compleja relación entre el individuo y la realidad y, por extensión, en esa discusión entre el objeto y el sujeto. La complejidad de esta relación, engrosada además por las nuevas dinámicas de comunicación digital, revela la transformación operada, por cuanto, en la actualidad, son muchos los discursos artísticos y no artísticos virtuales o los espacios simulados que se han hecho habituales en nuestra vida cotidiana, pero que nos afectan en los modos de entender no sólo la identidad, sino, también la subjetividad (Gobantes Bilbao y Tarodo-Cortés, 2019). De hecho, nos atrevemos a afirmar que si, de manera común, todos tenemos un paisaje que nos ha influenciado, transformado o impactado, ahora entre esos paisajes también están los construidos por la realidad digital, donde es posible vivir experiencias como las proporcionadas por la realidad aumentada, en tres dimensiones, los videojuegos o los espacios creados por las instalaciones propias del arte digital. Dotar de movimiento los cuadros de Van Gogh, como hace el artista Luca Agnani (2013) no es sino un modo de de transformar paisajes existentes o de conformar paisajes artificiales -como ocurriese en los años 60 y 70 con el Land Art, del que el "Muelle en espiral" de Robert Smitson es un buen ejemplo-, son propuestas donde sustentar una nueva experiencia estética que transforma radicalmente nuestra mirada a la realidad que nos rodea. En el ámbito específico que nos ocupa, experiencias envolventes como el Rubayaat (2015), una caja diseñada para explorar el lenguaje, la traslación y el multiculturalismo en una práctica literaria digital, heredera, en parte, de la poesía visual o la ecfrasis y de tantas otras textualidades propuestas desde lo literario y su conexión con otras formas artísticas, responderían -si seguimos a Claudio Guillén (1992: 79)- a otros modos de amplificatio con los que construir otras lecturas del paisaje extendiendo los límites de lo literario.

Como consecuencia, el cambio en la propia concepción de lo ficcional y su expansión a otros espacios convergentes con lo literario, así como la paulatina transformación de la relación de autor y lector con el objeto artístico, modifica, sin lugar a dudas, el entendimiento de las relaciones entre el arte y el territorio, más específicamente, entre la literatura y el modo en cómo ésta crea o refleja nuestra 
propia relación con él. A ello hemos de añadir el proceso de ficcionalización que lleva a literaturizar espacios cotidianos, urbanos o rurales, potenciando a través de este proceso su revalorización desde intereses promocionales y turísticos. Esta dinámica bidireccional, lleva, por una parte, a recrear en la literatura lugares específicos, con la intención de promocionarlos, o renovar su interés por ellos, al tiempo que provoca, en sentido inverso, la transformación "literaria" de otros, a través de la reescritura de los nombres de locales, calles o rincones, ahora convertidos en escenarios o itinerarios que simulan los experimentados por los personajes novelísticos (Magadán y Rivas, 2011a y 2011b). No obstante, cabe advertir aquí que esta práctica ya venía refrendada por escritores y viajeros, cuando recreaban las ciudades leídas para volver a reescribirlas en sus propios textos (desde el Petrarca de las Cartas familiares y la ciudad de Roma, hasta "los Dickens" de Galdós o Pérez de Ayala). La diferencia estriba ahora no sólo en el alcance o fama de la noticia, sino en la cosificación y codificación de los lugares, utilizados como reclamo turístico y recurso económico. El excesivo interés en este sentido - unido al boom del denominado "turismo cultural"- provoca la modificación de la realidad en función de la ficción literaria, con lo que se produciría lo que se ha venido a denominar como la intervención -en el sentido de afectación y de actuación- de la literatura en el paisaje (Morales Sánchez, 2015: 150).

Por otra parte, y en estrecha conexión con lo anterior, cabe valorar cómo la literatura continúa reformulando la textualidad literaria con relación a la forma de manifestar o construir el paisaje. Resulta obvio que ciertas tipologías genéricas han sido especialmente prolíficas en lo que a la construcción de paisajes se refiere, comenzando por la novela o la poesía -se nos viene a la memoria, por ejemplo, "Las cosas" de Jorge Luis Borges: "Cántico doloroso al cubo de la basura", de Rafael Morales o "En mi poesía no hay" de Carlos Edmundo de Ory-, hasta extenderlo a las memorias, los libros de viaje o las autobiografías, parte de una larga tradición textual que ahora adquiere nuevas dimensiones con la expansión e hibridación hacia lo audiovisual.

En este sentido, parece obligado mencionar un asunto difícilmente eludible cuando hablamos de paisaje: el viaje ha sido históricamente un elemento catalizador del mismo, que, recreado de diferentes modos y en continuo cambio, presencia en la actualidad nuevas modalidades discursivas -híbridas, plurales en cuanto a códigos- confluyentes o visibles a través de toda una suerte de portales, blogs y webs, tremendamente interesantes de analizar, por cuanto constituyen el germen de nuevas estrategias discursivo-persuasivas, integradas en textualidades complejas que nos permiten explorar antes de experimentar (recorridos virtuales, textos audiovisuales, hologramas y un largo etc. de recursos). Incluso el espectáculo teatral, a partir de la concepción abierta desarrollada desde finales del XX, se continúa enriqueciendo ofreciendo no sólo otras posibilidades en cuanto a los espacios físicos de la representación, sino también en lo relativo a la improvisación e interacción propias de modalidades como la performance, originando diferentes tratamientos del espacio en cuanto a dimensión de representación.

Por último, aunque no podemos detenernos por la extensión que supondría abordarlo en toda su complejidad, resta por mencionar cómo las distintas propuestas estéticas, las visiones y modos de estilización -desde la Rota Virgili hasta la propia ecocrítica ya mencionada- así como las propias 
categorías de personaje y cronotopo, han interactuado en esa conformación literaria del paisaje de la que venimos hablando. El propio espacio, referente esencial, ha sido trabajado de modo que puede pasar de ser una categoría textual cuya función se limita a abrigar la acción, a ser personaje o protagonista indiscutible de una obra dada. Esa literaturización de la realidad viene marcada, como no podía ser de otra forma, también, por el modo en el que la estética ha entendido la propia literatura y su modus operandi, en cómo ha reflejado la realidad para mostrarla, combatirla, negarla o alejarse de ella. Las palabras de Cernuda son ilustrativas de esa dialéctica entre escritor y el estatus otorgado a la realidad:

\footnotetext{
El deseo me llevaba hacia la realidad que se ofrecía ante mis ojos como si sólo con su posesión pudiera alcanzar certeza de mi propia vida. Mas como esa posesión jamás la he alcanzado sino de modo precario, de ahí la corriente contraria, de hostilidad ante el irónico atractivo de la realidad. Puesto que, según parece, ésa o parecida ha sido también la experiencia de algunos filósofos y poetas que admiro, con ellos concluyo que la realidad exterior es un espejismo y lo único cierto mi propio deseo de poseerla. (Cernuda, 1975)
}

Tampoco tenemos que olvidar que la escritura del espacio está muy ligada al desarrollo de técnicas narrativas como la descripción. De hecho, las distintas corrientes han entendido de manera diferente tanto el fin como el modo de ejecución de la misma -pongamos por caso el realismo y el naturalismo- según el modo de afrontar la observación y el análisis, en un conjunto de elementos relacionados con el tema de la "mirada", cuyo estudio resulta revelador. Recordemos también, cómo estas técnicas literarias están estrechamente ligadas con el desarrollo científico de los dispositivos ópticos, proporcionando formas dispares de mirar la naturaleza y también de contarla (Cantos Casenave, 2013).

De forma complementaria, desde el punto de vista de la lectura literaria, el acercamiento al paisaje se realiza a partir de presupuestos diferentes, relacionados tanto con el mundo interior de la obra como con lo derivado de las relaciones intertextuales y contextuales de la misma. La literatura reafirma la condición del ser en un paisaje específico, constituyéndose el acercamiento a esos espacios imaginados o recreados en excusa directa para que los lectores viajen (física o imaginariamente) para internarse en los mundos vividos por sus autores preferidos. La lectura estética deberá abordar no solo los resortes creativos que han originado esta construcción, sino, al mismo tiempo, las diferentes interpretaciones superpuestas, de manera que comprenderá al mismo tiempo la intersección de varios procesos sin los cuales sería imposible llegar a la comprensión crítica y al goce estético. Algo así como un doble proceso, en el que la interpretación debe advertir o captar algo ya interpretado, mediante el entrenamiento de la percepción y de la sensibilidad (Morales Sánchez, 2019). Uno de los aspectos más interesantes, en este sentido, es el acercamiento al concepto de empatía y su aplicación al estudio del paisaje. En efecto, el sentimiento de identificación con el territorio y todo aquello que participa de él está en clara consonancia con la tendencia actual que plantea una visión holística del paisaje, desterrando la tradicional separación entre objeto y sujeto, entendiéndolos como partes armónicas de un todo. En este sentido, algunos estudios subrayan el hecho estético como uno de los principales cauces generadores de esos símbolos, imágenes o significados que conforman el sentido identitario de una comunidad, entendiendo que el individuo es mucho más receptivo a todo aquello que sea 
emocional frente a lo racional (Albelda y Sgaramella, 2015: 13-14). Trasladado al ámbito literario, la irrupción de la ecocrítica, en tanto estudio dirigido a analizar la relaciones de la literatura con la naturaleza y cuyo texto fundacional en España viene de la mano del grupo Gieco, de la Universidad de Alcalá (Flis Junkera, Marrero Henríquez y Barella Vigal, 2010) y de la denominada lectura ecológica, definida como "una lectura con fines específicos, donde los contenidos son especialmente selectivos, al abordar cuestiones o tópicos por ejemplo de los ecosistemas" (Campos Figares y García Rivera, 2017: 99), abren una importante vía de exploración, al orientar el estudio desde la simbiosis del individuo con el territorio. Además de esta tendencia, cabe subrayar la complejidad abierta por la literatura digital y su tratamiento de espacios, cuya condición real, virtual o audiovisual, establecen una relación interactiva con el receptor, ofreciendo nuevas posibilidades de exploración, en la línea expuesta con anterioridad y relacionada con el arte digital.

Por lo tanto, el análisis del paisaje a través de la literatura posee numerosos vértices, que podríamos identificar, de forma general, mediante los siguientes ítems, organizados o no como se propone a continuación: ficción literaria / verosimilitud / identidad/ subjetividad - objetividad; Personaje / identidad/ mirada interior - exterior /interacción; Paisaje / construcción lingüística / técnicas discursivas; Espacio-tiempo /técnicas de construcción / invención, lectura, relectura, reinterpretación de los espacios heredados de la tradición; Símbolos, motivos y temas; (literatura comparada), paisaje/literatura/intertextualidad/estética/ideología; paisaje/ lectura estética/ lecturas del paisaje -a partir de otros textos, testimonios, relatos, discursos/a partir del viajelectores/lectoescritores.

\section{Un apunte más sobre Paisaje y Teoría de la literatura}

Pasa el agua del río, pero no su rumor, que es nuestro, no del río Fernando Pessoa, Aforismos

El estudio del paisaje a través del análisis de los discursos implicados en la literatura supone comprender el hecho literario en toda su complejidad y amplitud. A partir de este planteamiento, es preciso subrayar la necesidad de explorar metodologías mixtas, hipertextuales, si usamos un concepto fácilmente aplicable en el contexto digital actual, para abordar la dinámica que regula la relectura, reelaboración o construcción de paisajes a través de la literatura. Es obvio que los referentes filosóficos, históricos, antropológicos y también estéticos que subyacen a la configuración del paisaje conforman discursos a veces entendidos como literarios, a veces como pseudoliterarios. La concepción voluble y flexible de la literatura y su configuración en géneros en constante transformación hacen que el estudio del paisaje pueda ser abordado desde el centro mismo del modo en cómo se concibe la propia noción de discurso literario, además de su propia finalidad. Este último aspecto, resulta especialmente interesante, si planteamos no sólo cómo el paisaje ha servido para transmitir el modo en como el hombre piensa la naturaleza, sino, también, cómo ha sido un recurso discursivo para ejemplificar, amplificar o distender la narración; para convertirlo, literalmente, en metáfora de la relación del sujeto 
con el objeto, incluso, en recurso persuasivo. Entendiendo, por lo tanto, que hablamos tanto de contenidos como de técnicas y estrategias discursivas relacionadas con la intelectio, la dispositio, y la elocutio, y que el valor literario del paisaje trasciende al ámbito de lo artístico para resultar el reflejo o la materialización de valores ideológicos y sociales, la validez de nuestra propuesta sólo puede entenderse desde un planteamiento que evidencie la confluencia de la Teoría de la literatura con la Retórica y la Literatura comparada: la primera porque permite analizar los resortes que articulan el hecho literario; la segunda, porque permite un estudio de las estrategias discursivas con una finalidad persuasiva y, la tercera, porque desde su propia génesis, permite abordar la otredad y la identidad desde ángulos esenciales implicados en el propio concepto de paisaje. Hemos de recordar como históricamente, la Poética y la Retórica han sido las disciplinas de estudio del hecho literario, estableciendo una dialéctica continua que produce ese grado de literaturización de la retórica y retorización de la poética dada en diversos grados a lo largo de la historia pero que, de manera evidente, forma parte de la teoría literaria (Abad Nebot, 1989: 29). Atendiendo a formulaciones más recientes, resulta especialmente eficiente el concepto de Retórica cultural, articulado por el profesor Albaladejo Mayordomo en los últimos años, a partir de los presupuestos planteados por la semiótica de la cultura -articulada desde La Escuela de Tartu (Lotman) en los años 60 del pasado siglo- y que también comparte intereses, objetivos y orientaciones críticas con los Estudios Culturales, los Estudios Antropológicos y Etnológicos de la cultura o el Análisis y la Crítica de la cultura.

Esta perspectiva de análisis incide en la consideración de cualquier discurso como práctica cultural y, por lo tanto, enfoca cómo determinadas realidades articuladas por el discurso artístico son luego asumidas por una cultura, realidades que no existen materialmente sino que son la interpretación literaria de un territorio, no se articula sin la interacción de discursos literarios y no literarios. Ello permite abordar no solo la dimensión interpretativa, sino también creativa, aquella que permite que paisajes como los de Transilvania, hayan sido modelados a la luz de la tradición literaria vampírica, o que ciudades como Sevilla, adapten su fisonomía para evidenciar el paso por sus calles de Juego de Tronos. También que las políticas de protección de los humedales, o las políticas de contaminación urbanística, provocan un tratamiento artístico literario que va más allá de la configuración narrativa del espacio (el caso de las novelas de Rafael Chirbes, por ejemplo). Más concretamente, este sistema metodológico analiza las relaciones establecidas entre la cultura y la Retórica por medio del análisis de discursos retóricos generados en obras literarias y de otra índole y los efectos perlocucionarios que estos tienen sobre los receptores de estos discursos (Albaladejo, 2016). A partir, de nuevo, de la Retórica, permite sin embargo extender su uso a todo tipo de discursos -incluido el digitalpermitiendo la indagación también en los efectos que producen, de manera que enfatiza la dimensión cultural y el trasvase de valores entre unos y otros, evidenciando su interconexión. En lo que respecta a la dimensión ideológica de los discursos, la Retórica cultural entra en contacto con los Estudios culturales, aportando una metodología que aborda los aspectos semióticos de la comunicación (Albaladejo, 2009: 16). 
Pero quizá lo más interesante de este enfoque sea cómo evidencia la retoricidad de los discursos y su dimensión persuasiva, muy útil en el caso del estudio del paisaje, pues permite abordar aspectos que tienen que ver con su finalidad y su función social. Es evidente, por otra parte, que el éxito pongamos por caso- del turismo cultural está en parte relacionado con el descubrimiento de la cultura como un reclamo publicitario muy rentable económicamente, provocando la confluencia de la tradición heredada con otras cuyo dudoso origen hacen pensar en una reinvención, del pasado en aras de la construcción de una referencia o icono que pueda ser usado como representativo.

En el ámbito de la Neorretórica, la Retórica cultural supone, como sabemos, una forma de acercamiento a las categorías y paradigmas interpretativos que expanden fructíferamente las posibilidades de la Retórica al estudio de la cultura (Chico Rico, 2015: 310). Por último, su clara orientación comparatista no solo entre obras literarias, sino también entre elementos que forman parte de otros tipos de discurso, permite la confluencia con estudios de literatura comparada bajo lo que podría entenderse como un aparato metodológico amplio.

También con relación a la Retórica, en cuanto a los modos de narrar, David Pujante (2018) explica cómo la verosimilitud retórica tiene una relación estrecha con el carácter constructivo que de la realidad hacemos a través del discurso. Cuando no tenemos -dice literalmente- otra manera de acercarnos a la verdad sino haciendo una construcción verosímil de los hechos, el mecanismo de verosimilitud es clave para establecer nuestra visión de las cosas del mundo y está en relación directa con nuestra ética. Para un retórico la verosimilitud está en función de la utilitas, es un elemento fundamental de la finalidad pragmática de la narración y, en consecuencia, del discurso en el que se inserta. La narrativa retórica - continúa afirmando- ha puesto las bases de la teoría de la narrativa literaria, porque los seres humanos siempre interpretamos en una trama, y da lo mismo que sea literaria o histórico-social.

Por último, la exploración de la interdiscursividad permite el uso del material resultante desde cualquier perspectiva o enfoque, lo que acrecienta el valor transversal de la literatura y su utilidad para abordar temáticas vinculadas al paisaje: la configuración de la mentalidad urbana, la dialéctica de la identidad global a partir del diseño industrial vigente en los centros comerciales, las aplicaciones de la realidad virtual a la construcción de espacios interpretativos, discursividad de los paisajes digitales y un largo etc.

Otros estudios significativos son los estudios de poética llevados a cabo por M. ${ }^{a}$ Isabel López Martínez en torno a Góngora y su vinculación con Extremadura (2002), los topoi en Vicente Aleixandre (1990) o la poética de las ruinas (2009); los orientados hacia el discurso crítico literario realizados por Goldfard (2012), así como el estudio de los discursos de identidad, tanto relacionados con la idea de nación (Vilariño Picos, 2004) como, desde la retórica constructivista, los llevados a cabo por Pujante Sánchez (2018) y magníficamente ejemplificados en el estudio de las diferentes interpretaciones culturales que se han hecho de la melancolía en la historia cultural de Occidente, mediante el tratamiento del mito y de sus interpretaciones artísticas, religiosas y filosóficas. 
Por último, la utilización de la literatura como motor económico y turístico ha dado como resultados estudios acercamientos interdisciplinares centrados en los espacios urbanos como, por ejemplo, el volumen de inminente publicación coordinado por Enrique Baena Visiones lingüísticas y literarias del paisaje urbano.

Pero quizá uno de los retos más importante por asumir sea la exploración de aquello que hibrida lo tradicional y lo digital. Las nuevas textualidades y su concepción híbrida y mestiza de la escritura y la lectura están modificando no sólo nuestros hábitos de comunicación, sino, también, el modo en como nos relacionamos con la realidad. Una realidad en constante tensión entre lo natural y lo virtual, que genera espacios, incluso, generados por ordenador. Es aquí cuando cabe analizar si existe un tipo de paisaje derivado, por ejemplo de bots literarios o escritura automática y si, de alguna manera, seremos capaces de asimilarlo a nuestro pensamiento, afectando la forma en como interaccionamos con la naturaleza. También la revolución alimentaria forma parte de muchos de estos procesos y esto afecta a la construcción de la identidad y del territorio.

Para terminar, y puesto que uno de los objetivos de este breve acercamiento ha sido reivindicar un mayor desarrollo de los estudios interdiscursivos a partir del discurso literario y la forma en cómo aborda eficazmente el estudio del paisaje, proporcionando un marco sincretizador y plural, enumeramos alguna líneas de trabajo - unas claramente tradicionales y consolidadas, otras más recientes- que incorporamos constantemente en nuestra actividad docente e investigadora, con el objetivo de potenciar la integración de la teoría de la literatura y la propia literatura en estudios transversales e interdisciplinares. En este sentido, entendemos que el estudio del paisaje es un ámbito en el que la teoría y los estudios literarios deben ser integrados para formar parte de la formación profesional y académica, en tanto permiten la apertura a determinados campos como el patrimonio o la gestión cultural hasta ahora poco orientados o ignorados, aun cuando son una vía de estudio y especialización profesional muy importante en el contexto actual de las humanidades:

a) Literatura y paisaje: teoría general de sus relaciones. Exploraciones del paisaje a través de textos literarios y pseudoliterarios.

b) El artificio literario. Cómo se lee la realidad. La naturaleza como punto de partida de la construcción ficcional. Paisajes creados por la literatura.

c) El espacio como elemento vertebrador de la construcción paisajística. Teorías estéticas basadas en la construcción espacial.

d) Ideas literarias en la construcción del imaginario y del patrimonio cultural. Transversalidad e intertextualidad con otros discursos. El paisaje global (discursivo).

e) Literatura, paisaje, turismo y gestión cultural. Paisajes del agua.

f) Literatura, paisaje e identidad. Nacionalidades, fronteras, marginalidades y avatares.

g) El paisaje y su configuración estética y filosófica: estrategias persuasivas y construcción de realidades conceptuales y lingüísticas. El caso de los humedales. 
h) Intertextualidad y paisaje. La construcción de imaginarios.

i) Desubicación y destrucción de paisajes originales. El caso de Rafael Chirbes.

j) Hibridez, fragmentación, modelos de mundo, hábitos de lectura y modelos de escritura. Paisaje digital.

\section{Bibliografía}

Abat Nebot, F. (1987-89) Retórica, Poética y Teoría de la literatura, Estudios románicos, 4 (Ejemplar dedicado a: Homenaje al profesor Luis Rubio (I)), págs. 27-36.

Albaladejo, T. (2016). Cultural Rhetoric. Foundations and perspectives, Res Rhetorica, 1/2016, 17. (2009) La poliacroasis en la representación literaria: un componente de la Retórica cultural. Castilla. Estudios de Literatura, 0, 1-26.

Albelda, J., y Sgaramella, Ch. (2015) Arte, empatía y sostenibilidad. Capacidad empática y conciencia ambiental en las prácticas contemporáneas de arte ecológico, Ecozon, 6/2: 15-25.

Barros Caneda, J. R. (1996) Arquitectura doméstica en el Puerto de Santa María. La Casa de los Rivas, Laboratorio de arte, 9, 345-357.

Besse, J.-M. (2006) Las cinco puertas del paisaje en Maderuelo, J. (dir) Paisaje y pensamiento, Madrid, Abada editores, 2006: 145-171.

Campos Figares, M. y García Rivera, G. (2017) Aproximación a la Ecocrítica y a la Ecoliteratura. Literatura juvenil clásica e imaginarios del agua, Ocnos, 16 (2): 95-106 DOI 10.18239/ocnos_2017.16.2.1511.

Cantos Casenave, M. (2013) Los dispositivos ópticos y su recepción en la prensa del romanticismo (135-1868). Una aproximación, Anales de literatura española, 25, (Ejemplar dedicado a: Revistas literarias españolas e hispanoamericanas (1835-1868) / coord. por José María Ferri Coll, Enrique Rubio Cremades), págs. 105-130.

Cernuda, L. (1975) "Palabras antes de una lectura" en Prosa Completa. Barcelona, Barral.

Chico Rico, F. (2015): La Retórica cultural en el contexto de la Neorretórica, Dialogía: Revista de Lingüística, Literatura y Cultura, 9, 304-322.

Claudon, F. (1996) El paisaje en literatura comparada en Villanueva, D. (Ed.), Cabo Aseguinolaza, F. (eds.) Paisaje, juego y multilingüismo. Actas del X Simposio de la Sociedad Española de Literatura General y Comparada (Santiago de Compostela, 18-21 de octubre de 1994). 2 volúmenes. Cursos e Congresos da Universidade de Santiago de Compostela, 91, vol. I: pp. 201208).

Diaz Rojo, J. A. (2004) Lengua, cosmovisión y mentalidad nacional, Tonos digital, 7, 2004. disponible en https://www.um.es/tonosdigital/znum7/estudios/clengua.htm.

Etter, A. (1991) Introducción a la ecología del paisaje. Un Marco de Integración para los Levantamientos Ecológicos. 10.13140/2.1.4464.5121. 
Flys Junquera, C., Marrero Henríquez, M. y Barella Vigal, J. (2010) Ecocríticas. Literatura y medio ambiente, Madrid, Iberoamericana Vervuet.

Goldfarb, J. D. (2012) On lanscape criticis and literary criticism, Landscapes: the Journal of the International Center por Landsape adn Language, vol 5, (1). http://ro.ecu.edu.au/landscapes/vol5/iss1/15. Fecha de consulta [10/04/2019].

Gobantes Bilbao, M. y Tarodo-Cortés, D., coords. (2019) Discursos de la subjetividad contemporánea: de la Poética al videojueg0, Tropelías, Núm. 31.

Guillén, C. (1992) Paisaje y Literatura, o los fantasmas de la otredad, Actas del X Congreso de la Asociación Internacional de Hispanistas: Barcelona, 21-26 de agosto de 1989, Barcelona, Promociones y Publicaciones Universitarias, 1992, pp. 77-98.

(1996) El hombre invisible. Paisaje y literatura en el siglo XIX en Villanueva, Darío (Ed.), Cabo Aseguinolaza, Fernando (ed.) «Paisaje, juego y multilingüismo». Actas del X Simposio de la Sociedad Española de Literatura General y Comparada (Santiago de Compostela, 18-21 de octubre de 1994). 2 volúmenes. Cursos e Congresos da Universidade de Santiago de Compostela, 91 (1996), vol I: 67-83.

Hernández Guerrero, J. A. (2002) “Los paisajes literarios”, Castilla, núm. 27, pp. 73-84.

López Martínez, M. I. (1990) Tierra madre y hombre de barro: 'topoi' en la poesía de Vicente Aleixandre, Anuario de estudios filológicos, 13, 1990, págs. 167-184.

(2002) Apuntes de geografía literaria: Góngora y Extremadura, Revista de estudios extremeños, 58/3, 2002, págs. 845-862.

- (2009) Antecedentes clásicos de la poética de las ruinas, Teoría y análisis de los discursos literarios: estudios en homenaje al profesor Ricardo Senabre Sempere / coord. por Salvador Crespo Matellán, pp. 227-234.

Maderuelo, J. (2010) El paisaje urbano, Estudios geográficos, LXXI, 269, pp. 575-600, doi: 10.3989/estgeogr.201019.

Magadán Díaz, M. y Rivas García, J. (2011a) El legado literario y la creación de espacios turísticos, en Argüelles-Meres, L, Literatura y Turismo, Oviedo: Septem ediciones: 11-21.

(2011b) Turismo literario, Oviedo, Septem ediciones, 2011.

Mendoza Fillola, A. (2001) El intertexto lector. El espacio de encuentro de las aportaciones del texto con las del lector, Cuenca, Publicaciones Universidad Castilla-La Mancha.

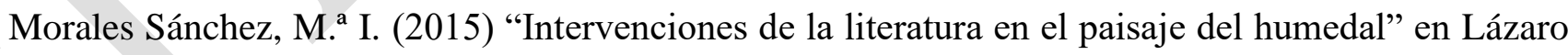
Gabriel Lagóstena Barrios (ed.), Qui lacus aquae stagna paludes sunt... Estudios históricos sobre humedales en la Bética, Tréveris, Cádiz, pp. 149-186.

(2019) "La lógica de la lectura: De la lectura estética o "el arte de leer con sentido" en Elsa Margarita Ramírez Leyva (Coord.), De la lectura académica a la lectura estética, México, Instituto de Investigaciones Bibliotecológicas y de la Información, UNAM, Colección Lectura: pasado, presente y futuro. 
170 | Tropelías. Revista de Teoría de la Literatura y Literatura Comparada, número extraordinario 5 (2019) María Isabel Morales Sánchez

Pujante, D. (2018) Pensamiento al margen. Revista digital, 9, 2018. ISSN 2386-6098 http://www.pensamientoalmargen.com.

Roger, A. (2007) Breve tratado del paisaje. Madrid, Biblioteca Nueva.

Vilariño Picos, M. T. (2004-2006) Paisajes, geografía literaria e identidad nacional, Tropelias: Revista de teoría de la literatura y literatura comparada, ISSN 1132-2373, 15-17, págs. 81-99.

Zimmer, J. (2008) "La dimensión estética del paisaje" en Nogué, Joan El paisaje en la cultura contemporánea, Madrid, Biblioteca nueva, 2008, pp. 27-44. 